\title{
EFEKTIVITAS BERMAIN "LEGO” UNTUK ENINGKATKAN PERKEMBANGAN KOGNITIF BERPIKIR SIMBOLIK ANAK USIA 4 - 5 TAHUN
}

\author{
THE EFFECTIVENESS OF PLAYING “LEGO” TO IMPROVE THE COGNITIVE \\ DEVELOPMENT OF CHILDREN'S SYMBOLIC THINKING AGE 4 - 5 YEARS \\ Rizqi Syafrina ${ }^{(1)}$, Vivi Endang Adiningsih ${ }^{(2)}$
}

Program Studi Pendidikan Guru Pendidikan Anak Usia Dini Universitas Widya Gama Mahakam Samarinda ${ }^{(1)}$, Program Studi Pendidikan Guru Pendidikan Anak Usia Dini Universitas Widya Gama Mahakam Samarinda (2)

E-mail: nonon11185@gmail.com ${ }^{(1)}$,vivifandi26@gmail.com ${ }^{(2)}$

\begin{abstract}
Abstrak : Bermain bagi anak usia dini memiliki banyak manfaat, dimana anak akan merasa bahagia ketika bermain. Selain itu bermain juga dapat membantu anak usia dini dalam mencapai perkembangannya secara maksimal. Santrock (2002) mengatakan permainan merupakan kegiatan yang dilaksanakan untuk kepentingan kegiatan itu sendiri. Anak usia dini menyukai aktivitas bermain, dimana mereka melakukannya dengan senang. Di kota Samarinda ada salah satu tempat kursus yang menawarkan permainan "lego". Peminat di tempat kursus ini cukup banyak, mereka memiliki banyak cabang di kota-kota besar di Indonesia. Orangtua memiliki harapan mendapatkan manfaat yang positif dengan mengikutkan anak kursus bermain "lego". Selain itu banyak artikel di media sosial yang menuliskan mengenai manfaat bermain lego, sehingga orangtua memiliki minat untuk mengikutkan anak kursus bermain "lego". Penelitian ini bertujuan untuk mengetahui efektivitas bermain "lego" untuk meningkatan perkembangan kognitif berpikir simbolik pada anak usia 4 - 5 tahun. Penelitian ini menggunakan metode Pre Experimental Design atau juga sering dikenal dengan Quasi Experiment. Bentuk rancangan eksperimen yang digunakan adalah The One Group Pretest-posttest Design. Pelaksanaan penelitian ini menggunakan desain kelompok tunggal dengan pretest dan posttest yang dilakukan dengan cara melakukan percobaan terhadap satu kelompok, tanpa menggunakan kelompok pembanding. Subjek penelitian ini adalah anak-anak yang mengikuti kursus "lego" di Robokidz Samarinda sebanyak 4 orang, dengan usia 4-5 tahun. Instrumen pengukuran ini menggunakan lembar observasi perkembangan kognitif berpikir simbolik dan wawancara semi-terstruktur dengan orangtua. Hasil penelitian menunjukkan jika bermain "lego" tidak meningkatkan perkembangan kognitif berpikir simbolik $(\mathrm{z}=-1.857, \mathrm{p}=0.063)$ secara siginifikan pada anak usia $4-5$ tahun. Namun, modul di Robokidz mampu menjalankan fungsinya untuk meningkatkan perkembangan kognitif berpikir simbolik anak usia 4-5 tahun berdasarkan hasil observasi secara individual pada kelompok eksperimen.
\end{abstract}

Kata Kunci : Bermain Lego, Perkembangan Kognitif Berpikir Simbolik

Abstract : Playing for children with early age has many benefits because they will feel happy when playing. Besides that, playing can also help them reach their maximum development potential. Santrock (2002) states that games are activities that carried out for the benefit of the activity itself. Children with early age likes play activities, which they do with pleasure. In the city of Samarinda, there is a course that offers "lego" games. There are quite a lot of enthusiasts in this course and they have many branches in major cities in Indonesia. The parents hope that they will get the positive benefits by taking their children to play "lego". Besides, many articles on social media write about the benefits of playing the game, so that parents have an interest in taking their children to take "lego" lessons. The purpose of this study is to determine the effectiveness of playing "lego" to improve the cognitive development of symbolic thinking in children aged 4-5 years. This research uses the Pre Experimental Design method or also known as Quasi Experiment. The experimental design used was The One Group Pretest-posttest Design. The implementation of this study used a single group design with a pretest and posttest which was carried out by experimenting on one group, without using a comparison group. The subjects of this study were 4 children who attended the "lego" course at Robokidz Samarinda, aged 4-5 years. The measurement instrument uses a symbolic thinking cognitive development observation sheet and semi-structured interviews with parents. The results showed that playing "lego" did not significantly improve the cognitive development of symbolic thinking $(z$ 
$=-1.857, p=0.063)$ in children aged 4-5 years. However, the modules in Robokidz can carry out their function to improve the cognitive development of symbolic thinking children aged 4-5 years based on the results of individual observations in the experimental group.

Keywords: Playing Lego, Cognitive Development of Symbolic Thinking

\section{PENDAHULUAN}

Bermain merupakan salah satu tekhnik pembelajaran anak usia dini. Setiap aktivitas yang dilakukan oleh anak usia dini dilakukan dengan bermain. Bermain bagi anak usia dini memiliki banyak manfaat, dimana anak akan merasa bahagia ketika beraktivitas, namun juga dapat membantu anak usia dini dalam mencapai perkembangannya secara maksimal. Santrock (2002) mengatakan permainan merupakan kegiatan yang dilaksanakan untuk kepentingan kegiatan itu sendiri. Anak usia dini menyukai aktivitas bermain, dimana mereka melakukannya dengan senang. Bermain merupakan merupakan kegiatan yang serius tetapi mengasikkan, bermain juga aktivitas yang dipilih sendiri oleh anak bukan untuk hadiah atau pujian (Trinova, 2012).

Dalam hal ini banyak pengembangan aneka tempat permainan yang dijadikan salah satu usaha yang cukup menjanjikan. Salah satunya adalah bermaian "lego". Menurut Utami dkk (2008) "lego" merupakan permainan konstruktif dari kepingan plastik yang dapat disusun dan dipasangkan menjadi suatu bentuk tertentu. Bermain "lego" sudah tidak asing lagi dan dimainkan oleh banyak anak di Indonesia, hal ini terlihat dari banyaknya toko mainan yang menjual mainan "lego". Selain itu ada klub bagi peminat permainan "lego" yang sudah ada di beberapa kota besar seperti Bandung, Surabaya dan Bali. Di kota Samarinda ada salah tempat kursus yang menawarkan permainan "lego" untuk anak. Berdasarkan hasil wawancara dengan salah satu orangtua yang mengikutkan anaknya kursus "lego", seorang ibu berusia 34 tahun memiliki satu anak usia lima tahun. Ia mengatakan jika anaknya senang sekali saat mengikuti aktivitas di tempat kursus "lego". Ibu ini menceritakan jika pada tempat kursus bermain "lego" ini memiliki kurikulum yang sama seluruh
Indonesia. Ibu ini mengatakan jika ia pernah mengunjungi tempat kursus "lego" yang ada di kota Jakarta, karena sebelumnya mereka tinggal di Jakarta. Menurut ibu tersebut anak tidak hanya diajarkan untuk bermain "lego", namun ada aktivitas lain sebagai bagian dari kurikulmunya. Akivitas tersebut seperti mewarnai, berhitung, menggambar atau memasangkan benda-benda sesuai dengan kategorinya. Namun tetap di setiap pertemuan yang dilakukan ada bermain "lego" yang menjadi aktivitas utama anak. Selain itu anak juga terlihat senang dan antusias ketika selesai mengikuti kursus bermain "lego", sehingga orangtua memiliki harapan mendapatkan manfaat yang positif dengan mengikutkan kursus bermain "lego". Selain itu banyak artikel di media sosial yang menuliskan mengenai manfaat bermain "lego", sehingga orangtua memiliki minat untuk mengikutkan anak kursus bermain "lego".

Selain itu "Lego" termasuk dalam kategori permainan konstruktif, terjadi ketika anak-anak melibatkan diri dalam suatu kreasi atau konstruksi suatu produk atau suatu pemecahan masalah ciptaan sendiri (Santrock, 2002). Menurut LeGoff (Suryadi, 2017) bermain "lego" dapat menunjukkan adanya keterampilan sosial yang lebih baik pada anak-anak yang mengalami autism dan gangguan komunikasi sosial lainnya. Terapi bermain ini juga meningkatkan kemampuan anak untuk merubah perilakunya, lebih memahami dan berbicara tentang perasaan mereka, menyelesaikan masalah dan belajar tentang dunia dimana mereka hidup, lebih baik daripada metode terapi bermain lainnya. Bermain "lego" dapat meningkatkan pola pikir dan kreativitas anak dengan metode bermain sambil belajar (Ningtyas, 2014). Piaget (Santrock, 2002) melihat permainan sebagai suatu media yang meningkatkan perkembangan kognitif anak-anak. Hal ini sesuai dengan yang dikatakan Rosita dkk (2013) bermain "lego" 
memiliki peranan yang penting dimana anak dapat mengembangkan kreativitasnya, memecahkan masalah sederhana dalam membentuk sebuah bangunan yang diinginkan.

Pada penelitian serupa, penelitian yang dilakukan Khasanah, Mustafidah dan Susanto (2018) dengan judul Modified Legos is Effective in Stimulating Development on Pre-School Children. Pada penelitian ini permainan "lego" sudah dimodifikasi dan untuk melihat perkembangan secara umum pada anak usia dini. Sedangkan penelitian yang dilakukan oleh peneliti materi permainan "lego" sesuai dengan kurikulum yang diberikan di tempat kursus bermain "lego" dan melihat perkembangan secara spesifik yaitu perkembangan kognitif berpikir simbolik pada anak usia dini. Menurut Hayati dkk (2017) suatu fase perkembangan kognitif ditandai dengan berfungsinya kemampuan berpikir secara simbolis. Penelitian lain yang dilakukan oleh Kartini dan Susilawati (2018) dengan judul Pengaruh Media Pembelajaran Lego Untuk Meningkatkan Kreativitas Anak Usia dini. Pada penelitian ini peneliti ingin melihat pengaruh media lego pada kreativitas anak usia dini. Sedangkan penelitian yang dilakukan bertujuan untuk melihat efektivitas bermain "lego" pada perkembangan kognitif berpikir simbolik pada anak usia dini.

\section{METODE}

Penelitian ini menggunakan metode Quasi Experiment atau Pre-Experimental Design. Bentuk rancangan eksperimen yang digunakan adalah The One Group Pretest-posttest Design yang menggunakan rancangan kelompok tunggal dengan pretest dan posttest yang dilakukan dengan cara melakukan percobaan terhadap satu kelompok, tanpa menggunakan kelompok pembanding (Shaughnessy dkk, 2007).

Analisis data yang digunakan untuk pengujian hipotesis penelitian ini adalah dengan analisis statistik, karena statistik bekerja dengan angka-angka yang bersifat objektif dan universal. Teknik analisis data yang digunakan adalah analisis kuantitatif dengan two related sample test dengan uji Wilcoxon. Uji tanda merupakan bagian dari statistik non parametrik yang menguji dua sampel yang saling berhubungan (Priyatno,
2012). Selain itu juga digunakan analisis deskriptif untuk melihat hasil observasi subyek perindividu.

\section{HASIL}

Analisis hasil dilakukan secara keseluruhan menggunakan analisa statistik uji dua sampel yang saling berhubungan (uji Wilcoxon). Priyatno (2012) mengatakan uji Wilcoxon ini digunakan untuk mengetahui ada tidaknya perbedaan antara dua kelompok sampel yang berpasangan. Analisis ini termasuk nonparametrik sehingga tidak mensyaratkan data berdistribusi normal. Dari data pretest dan posttest aspek perkembangan kognitif berpikir simbolik usia 4-5 tahun diketahui nilai Sig 0,063 (nilai sig > 0,05) berarti hipotesis ditolak yaitu tidak ada perbedaan perkembangan kognitif berpikir simbolik sebelum bermain "lego" (pretest) dan setelah bermain "lego" (postest).

Sedangkan berdasarkan hasil skor observasi perkembangan kognitif berpikir simbolik anak usia 4-5 tahun pada semua subjek dari sebelum bermain dan setelah bermain selama 2 bulan cukup mengalami peningkatan. Perbandingan skor tersebut dapat dilihat pada diagram di bawah ini:

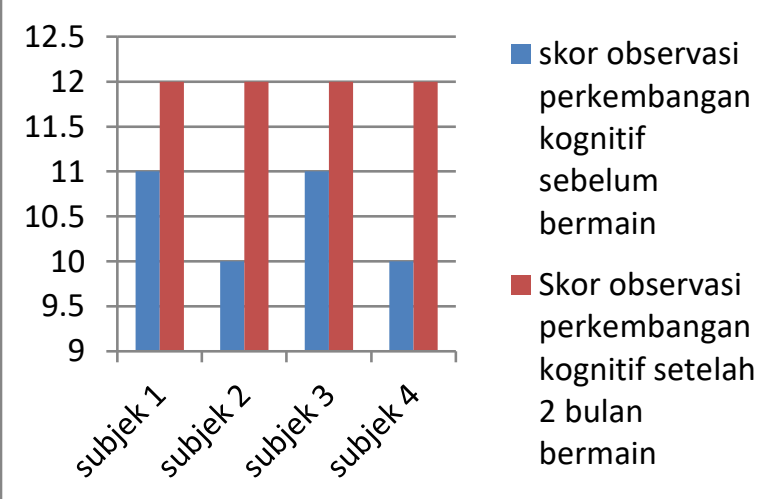

Diagram Perbandingan skor observasi perkembangan kognitif berpikir simbolik anak usia 4-5 tahun

Bermain "lego" yang diberikan dalam penelitian ini bertujuan untuk meningkatkan perkembangan kognitif berpikir simbolik anak usia 4-5 tahun. Berdasarkan analisis data pretest dan posttest yang menggunakan uji Wilcoxon, diketahui tidak ada perbedaan antara data pretest 
dan data posttest dengan nilai sig 0,063 (Sig > 0,05). Sedangkan hasil pemaparan secara individual menunjukkan adanya peningkatan pada perkembangan kognitif berpikir simbolik anak usia 4-5 tahun.

\section{DISKUSI}

Tujuan dalam penelitian ini yaitu untuk mengetahui efektifitas bermain "lego" untuk meningkatkan perkembangan kognitif berpikir simbolik anak usia 4-5 tahun. Hasil penelitian menggunakan uji Wilcoxon menunjukkan tidak ada perbedaan antara data pretest dan data posttest dengan nilai sig 0,063 ( $\mathrm{Sig}>0,05)$. Pada penelitian ini diukur dengan menggunakan lembar observasi perkembangan kognitif berpikir simbolis anak usia 4-5 tahun berdasarkan Permendikbud 137 Tahun 2014. Pada saat pengambilan data posttest, perkembangan kognitif berpikir simbolik usia 4-5 tahun tercapai secara maksimal bahkan ada dua anak yang mencapai perkembangan kognitif berpikir simbolik anak usia 5-6 tahun. Hal ini menunjukkan jika lembar observasi yang digunakan kurang dapat mengukur secara maksimal perkembangan kognitif berpikir simbolik anak.

Selain itu kegiatan bermain "lego" ini tidak berjalan sesuai dengan perencanaan diawal. Awalnya terdapat 10 subjek yang akan diambil datanya. Namun pada akhirnya tidak semua anak mengikuti keseluruhan penelitian selama dua bulan, sehingga hanya 4 anak yang dapat diambil datanya. Kegiatan bermain "lego" dilakukan setelah pretest. Kegiatan bermain "lego" dilakukan selama dua bulan, dan kemudian diambil data posttest. Kegiatan bermain "lego" di Lembaga Robokidz dilakukan satu minggu sekali dengan durasi bermain selama 60 menit setiap pertemuan, sehingga setelah pretest ada delapan kali pertemuan dan kemudian diambil data posttest. Menurut Seniati dkk (2005), jika pelaksanaan penelitian tidak sejalan dengan perencanaan, maka dalam laporan penelitian perlu disampaikan mengapa penelitian tidak dapat sesuai dengan perencanaan. Pada penelitian ini terjadi experimental mortality di mana jumlah subjek pada akhir penelitian berkurang dibandingkan dengan awal penelitian (Seniati dkk, 2005).

Sedangkan berdasarkan pemaparan dan skor observasi secara individual diketahui anak mengalami peningkatan pada perkembangan kognitif berpikir simbolik anak usia 4-5 tahun. Hal ini sesuai dengan penelitian Poon (2018) menunjukkan jika 90\% dari subjek penelitiannya mengatakan bermain "lego' dapat meningkatkan kreativitas anak. Selain itu dikatakan bermain "lego" juga anak dapat mempelajari pemecahan masalah, berkomunikasi, kerja tim, meningkatkan koordinasi mata dan tangan, meningkatkan perkembangan motorik halus dan kasar, serta meningkatkan kemampuan interpersonal dan intrapersonal (Poon, 2018). Menurut Jensen (Poon, 2018) prinsip bisnis dari permainan "lego" menekankan pada imajinasi, inovasi dan kreativitas sebagai kesenangan dan pembelajaran. Menurut penelitian Utami dkk (2008) bahwa permainan lego dapat meningkatkan perkembangan kognitif.

Pada saat bermain "lego" di Robokidz, anak-anak memiliki modul selama setahun sesuai dengan tingkat usianya. Delapan pertemuan yang diambil untuk penelitian meliputi beberapa materi, diantaranya anak belajar angka, huruf dan mengenal tempat. Dalam hal ini, setiap bermain "lego" di Robokidz dapat ikut membantu mengembangkan perkembangan kognitif. Hal ini sesuai dengan pendapat yang diberikan oleh Karim dan Wifroh (2014) dimana salah satunya pentingnya pendidik mengembangkan kognitif yaitu anak mampu memahami simbol-simbol yang tersebar di dunia dan melatih ingatan terhadap semua peristiwa dan kejadian yang dialaminya. Pada beberapa pertemuan di Robokidz, anak belajar mengenai tempat seperti Cafe dan kebun binatang. Pada pertemuan tersebut anak diminta untuk membayangkan saat berada di kebun binatang dan Cafe serta anak diminta untuk mengidentifikasi apa saja yang mereka temui.

Menurut Susanto (Karim dan Wifroh, 2014) salah satu faktor yang mempengaruhi perkembangan kognitif yaitu faktor lingkungan. Hal ini menunjukkan pentingnya bagaimana lingkungan dapat membantu perkembangan kognitif anak, jika anak diberi stimulus dengan baik, maka perkembangan anak akan mengalami peningkatan. Menurut Locke (Karim dan Wifroh, 
2014) taraf inteligensi sangatlah ditentukan oleh pengalaman dan pengetahuan yang diperoleh dari lingkungan. Seperti dalam pertemuan dalam Robokidz, anak akan merasakan pengalaman saat membuat permainan "lego" dimana permainan tersebut menyesuaikan dengan tema yang sudah ditentukan. Anak akan membuat permainan "lego" berdasarkan apa yang sudah mereka alami.

Selain berdasarkan modul, pada setiap pertemuan bermain "lego" di Robokidz anak juga diberikan kebebasan untuk bermain "lego" sesuai dengan keinginan mereka. Disini anak akan mengembangkan imajinasinya dengan membuat sesuatu yang mereka inginkan dan kemudiannya mempresentasikan pada guru. Tujuan dari setiap pertemuan dalam bermain "lego" yaitu kreativitas dan mengembangkan imajinasi. Hal ini sesuai dengan pendapat Santrock (2002) bahwa dunia kognitif anak prasekolah adalah kreativitas, bebas dan imajinatif. Saat bermain "lego" anak terlihat senang, mereka terlihat bersungguh-sungguh saat sedang membuat sesuatu dan tertawa saat memainkannya. Hal ini sesuai yang diungkapkan oleh Yuliana dkk (2016) dalam penelitiannya, saat anak bermain "lego", anak-anak selalu merasa antusias dan senang karena mereka merasa sedang bermain bukan belajar. Selain itu media permainan "lego" yang aman membuat anak merasa nyaman. Menurut Sudono dan Mutiara (Hendriyani dkk, 2018) "lego" merupakan permainan yang menyenangkan karena mudah untuk dilakukan anak.

Pada permainan "lego" ini anak akan membuat sesuatu sesuai dengan tema yang ditentukan dan gambar yang diberikan. Pada pembuatannya, anak akan mencari bentuk "lego" yang sesuai yang ditunjukkan oleh gambar. Anak juga akan menghitung berapa jumlah "lego" yang akan mereka gunakan. Hal ini membantu anak dalam meningkatkan kemampuan berhitung anak. Menurut Asmara (2017) permainan "lego" digunakan untuk mengembangkan kognitif anak agar anak siap mengikuti pelajaran matematika di Sekolah Dasar. Perkembangan kognitif menurut peraturan Menteri Pendidikan dan Kebudayaan Republik Indonesia nomor 137 Tahun 2014 tentang standar Pendidikan Nasional Pendidikan Anak Usia Dini mengenai pencapaian perkembangan koginitif berpikir simbolik untuk anak usia 4-5 tahun salah satunya yaitu membilang banyak benda dari satu sampai sepuluh. Selain itu saat menentukan jumlah "lego" anak juga akan mengenal konsep bilangan. Sedangkan untuk aspek mengenal lambang bilangan dan lambang huruf dipelajari saat anak mengerjakan worksheet pada setiap pertemuannya. Seperti yang dilakukan Habsari dkk (2013), pada penelitiannya metode mengenal konsep bilangan pada anak umur 4-5 tahun dilakukan dengan metode bermain salah satunya yaitu bermain "lego".

Proses bermain "lego yang telah dilakukan dalam penelitian ini tidak memberikan pengaruh pada peningkatan pada perkembangan kognitif berpikir simbolik anak usia 4-5 tahun yang mengikuti kursus di Robokidz kota Samarinda. Pada saat bermain "lego" di Robokidz, subjek mengikuti kelas robokidz delapan kali pertemuan selama dua bulan. Pada penelitian ini tidak dilakukannya follow-up setelah posttest sehingga peneliti tidak dapat melakukan monitoring peningkatan perkembangan koginitif berpikir simbolik. Selain itu juga aspek yang terbatas pada perkembangan kognitif berpikir simbolik anak usia 4-5 tahun, sehingga saat pengambilan data posttest kemampuan anak yang diatas usianya tidak dapat terukur. Namun demikian, hasil deskripsi data penelitian menunjukkan 4 peserta mengalami peningkatan perkembangan kognitif berpikir simbolik. Hal ini menunjukkan bahwa bermain "lego" ini cukup mampu meningkatkan perkembangan kognitif berpikir simbolik untuk anak usia 4-5 tahun.

\section{KESIMPULAN}

Berdasarkan analisis data dan pembahasan yang dilakukan, maka dapat disimpulkan bahwa bermain "lego" dalam penelitian ini tidak dapat meningkatkan perkembangan kognitif berpikir simbolik anak usia 4-5 tahun secara signifikan. Meskipun demikian, berdasarkan analisis data deskriptif, bermain "lego" cukup mampu menjalankan fungsinya untuk meningkatkan perkembangan kognitif berpikir simbolik anak usia 4-5 tahun, yang ditunjukkan dengan meningkatnya skor observasi perkembangan kognitif berpikir simbolik anak usia 4-5 tahun pada 4 subjek penelitian. 
Beberapa hal yang perlu disempurnakan agar permainan "lego" pada penelitian-penelitian selanjutnya dapat memberikan hasil yang lebih optimal, untuk pihak Robokidz dapat dengan melihat tanggapan positif dari anak yang mengikuti kursus bermain "lego", pihak Robokidz dapat membuat modul bermain "lego" yang sesuai dengan usia namun dengan jangka waktu yang lebih pendek misal untuk tiga bulan atau untuk enam bulan. Hal ini menghindari anak-anak yang ikut kursus bermain "lego" cuti ditengah jalan, sehingga tidak maksimal ketika mengikuti kursus di Robokidz. Bagi guru dan praktisi lain, penelitian ini selanjutnya dapat dijadikan dasar ilmiah untuk kajian program bermain "lego" dalam suatu usaha meningkatkan perkembangan kognitif berpikir simbolik anak usia 4-5 tahun dan program bermain "lego" ini dapat ditetapkan sebagai stimulus anak untuk meningkatkan perkembangan kognitif berpikir simbolik anak usia 4-5 tahun. Sedangkan untuk peneliti selanjutnya perlu berkoordinasi dengan pihak Robokidz untuk memastikan keikutsertaan anak-anak yang menjadi subjek penelitian, benarbenar melakukan pendekatan personal pada anak dan orangtua peserta subjek penelitian dan memastikan kembali keikutsetaan anak, membuat lembar observasi yang dapat mengukur semua peningkatan aspek perkembangan anak, sehingga semua peningkatan perkembangan anak dapat terukur serta peneliti dapat membuat kelompok kontrol untuk pembanding.

\section{DAFTAR PUSTAKA}

Asmara, B. 2017. Penggunaan Permainan Lego Dalam Bidang Pengembangan Kognitif Untuk Meningkatkan Kreativitas Anak Usia Dini Di PPT Permata Bunda Kecamatan Wonocolo Surabaya. Education and Human Development Journal, Vo. 2, No. 2, Hal. 45-54. Diunduh dari https://journal2.unusa.ac.id/index.php/E HDJ/article/view/1380/962

Habsari, D., Syukri, M., \& Halida. 2013. Metode Pengenalan Konsep Bilangan Pada Anak Kelompok Umur 4-5 Tahun Di TK. Journal Pendidikan dan Pembelajaran
Khatulistiwa, Vol. 2, No. 1. Diunduh dari https://jurnal.untan.ac.id/index.php/jpdp b/article/view/802/pdf

Hayati, N., Cholimah, N., \& Christianti, M. 2017. Indentifikasi Keterampilan Kognitif Anak Usia 2-6 Tahun Di Lembaga PAUD Kecamatan Sleman, Yogyakarta. Jurnal Pendidikan Anak Vol. 6, Edisi 2. Hal. 181-189. Diunduh dari https://journal.uny.ac.id/index.php/jpa/is sue/view/1302

Hendriyani, Devita, Y., \& Mardalena. 2018. Pengaruh Bermain Konstruksi (Lego) Terhadap Perkembangan Motorik Halus Anak Usia Prasekolah. Jurnal Keperawatan Priority, Vol. 1, No.2 Hal 51-62. Diunduh dari http://jurnal.unprimdn.ac.id/index.php/ju kep/article/view/190

Karim, M.B. dan Wifroh, S.H. 2014. Meningkatkan Perkembangan Kognitif Pada Anak Usia Dini Melalui Alat Permainan Edukatif. Jurnal PG PAUD Trunojoyo Vol. 1 No. 2, Hal. 76-146. Diunduh dari https://journal.trunojoyo.ac.id/pgpaudtru nojoyo/article/download/3554/2621

Kartini dan Susilawati, I. 2018. Pengaruh Media Pembelajaran Lego Untuk Meningkatkan Kreativitas Anak Usia dini. Jurnal Pendidikan Anak Usia Dini, 1 (2), Hal. 33-43. Diunduh dari http://jurnal.stkippersada.ac.id/jurnal/ind ex.php/PAUD/article/download/386/371

Khasanah, N.N., Mustafidah, A., \& Susanto, H. 2018 Modified Legos is Effective in Stimulating Development on Pre-School Children. Jurnal Ilmu Keperawatan Anak, Vol 1 No. 2, Hal 16-21. Diunduh dari https://journal.ppnijateng.org/index.php/ jika/article/view/131

Khadijah. 2016. Perkembangan Kognitif Anak Usia Dini. Medan: Perdana Publishing. 
Ningtyas, F.Y. 2017. Metode Bermain Lego Dalam Upaya Menumbuhkembangkan Kecerdasan Kinestetik Pada Anak Usia Dini. Jurnal Empowerment Volume 4, No. 2, Hal. 128-134. Diunduh dari http://e-

journal.stkipsiliwangi.ac.id/index.php/e mpowerment/article/view/579

Poon, T. S. F. 2018. LEGO as a Learning Enabler in 21st-Century Preschool Classroom: Examining Perceptions of Attitudes and Preschool Practice. Journal of Urban Culture Research hal. 72-87. Diunduh dari

https://www.researchgate.net/publicatio $\mathrm{n} / 330310375$

Priyatno, D. 2012. Cara Kilat Belajar Analisis Data dengan SPSS 20. Yogyakarta: Andi Offset.

Rosita, Fadillah, \& Yuniarni, D., 2013. Pengembangan Potensi Kognitif Anak Melalui Bermain Konstruksi dengan Lego di TK. Kartika V-49 Pontianak. Jurnal Pendidikan dan Pembelajaran Khatulistiwa, Vol. 2, No. 3. Diunduh dari http://jurnal.untan.ac.id/index.php/jpdpb /article/download/1476/pdf

Santrock, J.W. 2002. Life Span Development Jilid 1. Jakarta: Erlangga

Seniati, L., Yulianto, A. \& Setiadi, B.N. 2005. Psikologi Eksperimen. Jakarta: PT. Indeks.

Setyani, M.R., Dita, S.W. \& Tunggadewi., I.N. 2017. Penerapan Lego Bricks dalam Pembelajaran sebagai Strategi untuk Meningkatkan Kecerdasan Matematis Siswa dalam Menghitung Bilangan Berpangkat. Jurnal Pendidikan Matematika Vol. 3, No. 1. Diunduh dari https://jurnal.umj.ac.id/index.php/fbc/art icle/view/1729

Shaughnessy, dkk. 2007. Metode Penelitian Psikologi. Yogyakarta: Pustaka. Pelajar.
Suryadi, D. 2017. Studi Awal Identifikasi Efek Terapi Bermain dengan Lego. Jurnal Ilmu Sosial, Humaniora dan Seni Vol. 1, No. $1 . \quad$ Diunduh dari https://journal.untar.ac.id/index.php/jmis humsen/article/view/356

Trinova, Z. 2012. Hakikat Belajar dan Bermain Menyenangkan Bagi Peserta Didik. Jurnal AL-Ta'lim, Jilid 1, No. 3, Hal. 209-215. Diunduh dari http://journal.tarbiyahiainib.ac.id/index. php/attalim/article/download/55/59/pdf

Utami, S., Qur'aniati, N., \& Kusuma, E. 2008. Bermain Lego Meningkatkan Perkembangan Kognitif Anak Usia Prasekolah (4-5 tahun). Jurnal Ners Vol. 3, No. 2. Diunduh dari https://ejournal.unair.ac.id/JNERS/article/view/4 993

Yuliana, Syukri, M., \& Halida. 2016. Pemanfaatan Permainan Lego Untuk Pengembangan Kecerdasan Visual Spasial Di TK. Jurnal Ilmu Pendidikan dan Pembelajaran Khatulistiwa, Vol. 5, No. 5. Diunduh dari https://jurnal.untan.ac.id/index.php/jpdp b/issue/view/598 